\title{
ACDF Using the Solis Cage with Iliac Bone Graft in Single Level: Clinical and Radiological Outcomes in Average 36 months Follow-up
}

\author{
Si-Hyuck Oh, Kyeong-wook Yoon, Young-Jin Kim, Sang-koo Lee \\ Department of Neurosurgery, Dankook University College of Medicine, Cheonan, Republic of Korea
}

\begin{abstract}
Objective: To evaluate the utility of anterior cervical discectomy and fusion (ACDF) with polyetheretherketone (PEEK) cage and autograft through long term (average 36 months) follow-up.

Methods: Thirty selected patients (male:20 /female:10) who suffered from cervical radiculopathy, myelopathy or radiculomyelopathy underwent a single level ACDF with PEEK cage and autograft from iliac crest from March 2006 to July 2008 in single institute. We followed patients for an average 36.4 \pm 8.1 months (ranged from 23 to 49 months). The Japanese Orthopedic Association (JOA) score for evaluation of myelopathy and visual analogue scale (VAS) for radiating pain was used to estimate postoperative clinical outcome. Plain x-ray on true lateral standing flexion, extension and neutral position view and 3D CT scan were used every 6 months after surgery during follow-up period.

Results: The mean VAS and JOA scoring improved significantly after the surgery and radiological fusion rate was accomplished by 100\% 36 months after the surgery. We had no complication related with the surgery except one case of osteomyelitis. There was one case of Grade I fusion, four cases of grade II, and 25 cases of grade III by radiologic evaluation. Conclusion: This long term follow-up study for ACDF with PEEK cage shows that this surgical method is comparable with other anterior cervical fusion methods in terms of clinical outcomes and radiologic fusion rate.
\end{abstract}

Key Words: Anterior cervical fusion - PEEK cage

\section{INTRODUCTION}

As the cervical spine degenerates with age, there is increased risk of undesirable conditions such as displacement or degeneration of intervertebral disc, slackness of annulus fibrosis, osteophytosis of vertebral body and instability. Degenerative cervical disc may cause posterior neck pain, radiating pain on arm or shoulder, or cervical myelopathy. Anterior cervical discectomy and fusion (ACDF) is a safe and standard operation for the treatment of degenerative cervical disc disease concerned with radiculopathy or myelopathy ${ }^{29)}$. The main purposes of intervertebral cage are biomechanical support, restoration of disc height, maintaining of cervical lordosis and ideal osteointegration $^{4,17,19)}$.

Tricortical iliac crest autobone graft results in numerous com-

\footnotetext{
- Received: April 25, 2013 - Revised: May 18, 2013

- Accepted: May 22, 2013

Corresponding Author: Young-Jin Kim, MD, PhD

Department of Neurosurgery, Dankook University College of Medicine, 201

Manghyang-ro Dongnam-gu, Cheonan 330-715, Republic of Korea

Tel: +82-41-550-3979, Fax: +82-41-552-6870,

E-mail: spine1225@naver.com
}

plications including breaking of bone graft, collapsing, pseudoarthrosis, subsidence, angular deformation, protrusion of bone block, pain or bleeding of donor site and infection ${ }^{22,30,31)}$. The most frequently donor site related complication is pain, and infection of harvest site could be a nettlesome problem ${ }^{23)}$. To solve these problems, various types of artificial cages providing immediate firmness without a plate system have been devised and applied to clinical fields ${ }^{18)}$.

A standard cage alone for ACDF is an effective method to treat degenerative cervical disease ${ }^{23}$. Short term clinical follow up data has been published less than 18 months after ACDF with the polyetheretherketone (PEEK) cage. In the current study, we present a retrospective long term (mean period: 36 months) study of thirty consecutive patients after ACDF with Solis ${ }^{\circledR}$ cage with iliac autobone graft.

\section{MATERIALS AND METHODS}

\section{Patient selection}

We collected information from charts of patients who visited our neurosurgical department from March 2006 to July 2008, retrospectively. Only patients with single level ACDF 
without anterior cervical plate were eligible for the study, and thirty patients were selected (male: 20 patients and female: 10 patients). The mean age was $47.6 \pm 7.1$ years (range from 28 to 63 years old). We included patients who complained of radiculopathy, myelopathy or both. The patients who complained of radiculopathy were 21, myelopathy were 2 and myeloradiculopathy were 7 patients. We included clinically diagnosed disc degeneration, imaging correlation and failure of conservative treatment. Mean follow-up period was 36.4 \pm 8.1 months (ranged from 23 to 49 months).

\section{Surgical procedure}

All surgeries were conducted by the same surgeon using a standard anterior cervical approach. A right side skin incision was done in all cases; fluoroscopy was used to check the target level. We used a Caspar retractor to detract vertebral bodies. Complete removal of the disc, lateral decompression and end plate flattening for maximal contact with cage was performed. After selection of ideal trial size by using intraoperative fluoroscopy, harvested cancellous bone from the iliac crest filled in the hollow space of the cage. The cage was gently placed and tapped into disc space by mallet. Finally, we checked that the radiopaque titanium spike was in an adequate location by fluoroscopy. We recommended a cervical brace for 2 months after the surgery.

\section{Clinical evaluation}

We used the Japanese Orthopedic Association (JOA) score for evaluation of myelopathy and visual analogue scale (VAS) for radiating pain to estimate postoperative clinical outcome. We assessed degree of pain relief between preoperative and postoperative (last follow-up) status by using two scoring systems.

Table 1. Demographic data

\begin{tabular}{ll}
\hline \hline Characteristic & $\mathrm{n}=30$ \\
\hline Sex \& Age & \\
Male/female & $20 / 10$ \\
Age & $47.6 \pm 7.1$ yrs (28-63) \\
Clinical manifestation & \\
Radiculopathy & 21 \\
Myelopathy & 2 \\
Myeloradiculopathy & 7 \\
Level & \\
C3-C4 & 5 \\
C4-C5 & 4 \\
C5-C6 & 11 \\
C6-C7 & 10 \\
f/u period & $36.4 \pm 8.1$ months (23-49) \\
\hline
\end{tabular}

We cited radiographic assessment which. Lee et al. suggested in 2009 and applied to our study design ${ }^{23}$. Three parameters were used to evaluate radiologic outcome: anterior disc height $(\mathrm{ADH})$, interbody height $(\mathrm{IH})$ and segmental interbody angle (SIA) (Fig. 1). They were checked by plain x-ray on true lateral standing and classified into flexion, extension and neutral position view and 3D CT scan every 6 months after the surgery. Fusion was defined according to trabecular bony formation across interfaces between cage and endplates and bony bridge formation between endplates. Fusion was classified into 3 classifications: grade I, bridging bone partially filling the cage; grade II, bridging bone filling the cage; and grade III, bridging bone within and around the cage ${ }^{26}$.

\section{RESULTS}

\section{Clinical outcome}

We compared VAS for neck and arm between preoperative and last follow-up status, additionally, JOA score was also used. Table 2 shows a summary of clinical parameters. The mean preoperative VAS for neck was $7.4 \pm 0.7$ and for arm was $7.9 \pm 0.8$. The mean VAS for neck at the last exam was $2.5 \pm 0.8$ and for arm was $3.2 \pm 1.1$ (p-value $<0.05$ ). In JOA scoring assessment for 9 patients who were suffered from myelopathy, score improved from $11.1 \pm 2.9$ at preoperative status to $14.5 \pm 2.6$ at last exam (p-value $<0.05$ ).

\section{Radiologic findings}

Among 30 cases, 22 patients were performed 3 dimensional CT scan (3D CT) at last follow-up and remainders were checked by cervical dynamic plain $\mathrm{x}$-ray. Radiological fusion rate was
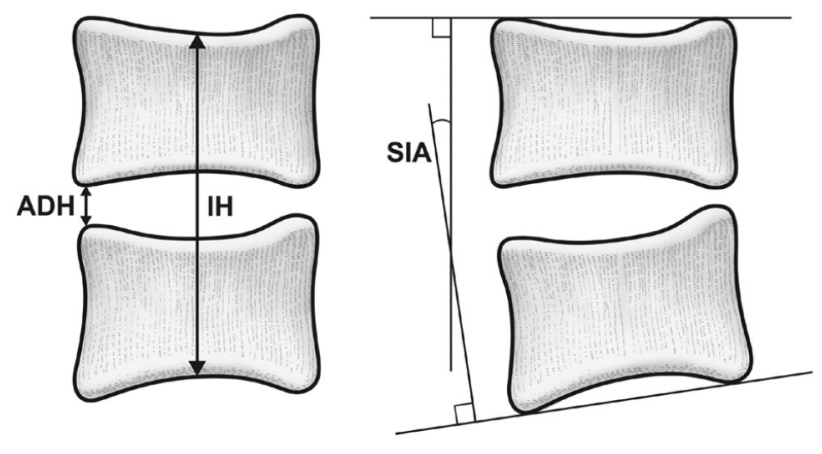

Lateral view

Fig. 1. Schematic picture of cenvical vertebra body (lateral view). $\mathrm{ADH}$ : anterior disc height, $\mathrm{IH}$ : interbody height, SIA: segmental interbody angle. 

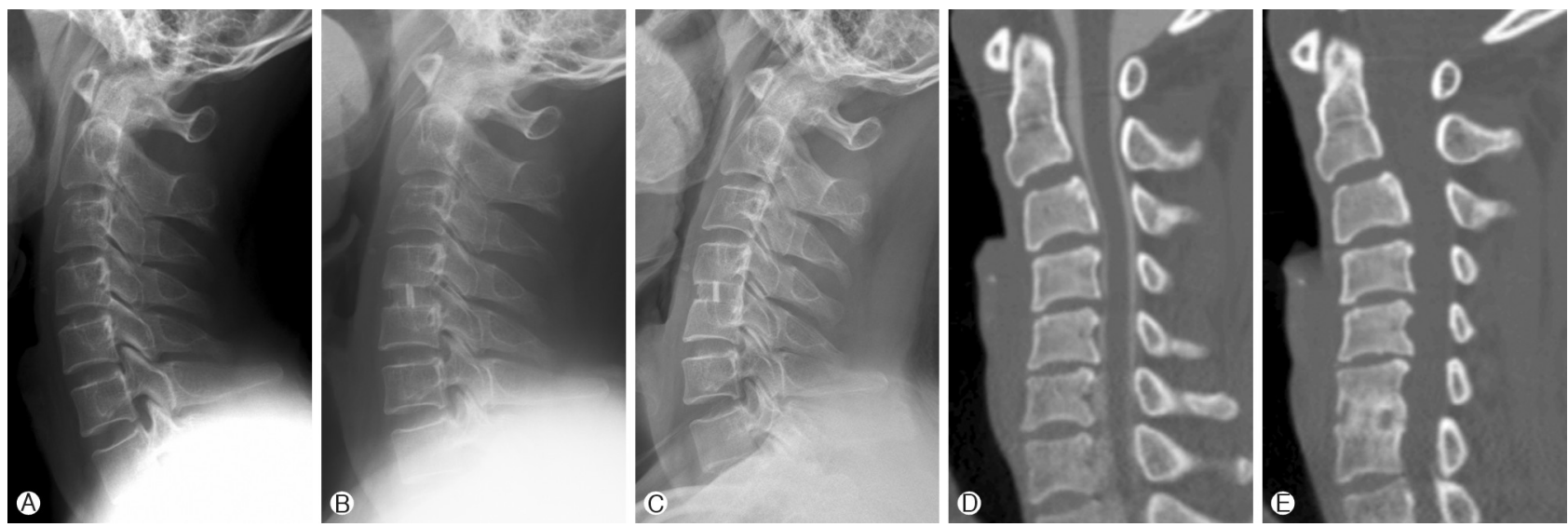

Fig. 2. A-C: Serial plain X-ray of one patient shows bony bridge formation between C4 and C5 body. (A: preoperative X-ray film, B: postoperative X-ray film, C: last follow-up X-ray film) D, E: 3D CT scan shows grade III fusion comparing preoperative and last exam in one patient. (D: preoperative 3D CT, E: last follow-up 3D CT)

Table 2. The mean values of clinical parameters measured before surgery, and at the last follow-up

\begin{tabular}{lccc}
\hline \hline Parameters & Preoperative & \multicolumn{1}{c}{ Last $\mathrm{f} / \mathrm{u}$} & $\mathrm{p}$ (t-test) \\
\hline VAS (neck) & $7.4 \pm 0.7$ & $2.5 \pm 0.8$ & $<0.05$ \\
VAS (arm) & $7.9 \pm 0.8$ & $3.2 \pm 1.1$ & $<0.05$ \\
JOA score & $11.1 \pm 2.9$ & $14.5 \pm 2.6$ & $<0.05$ \\
\hline
\end{tabular}

accomplished by $100 \%$ in selected group after 36 months after the surgery. Grade I fusion were found in 1 case, grade II were in 3 cases and grade III were in 18 cases on 3 DCT scan. On plain X-ray, grade I fusion was no case, grade II were 1 cases and grade III were 7 cases (Fig. 2). Table 3 shows mean values of radiological parameters. The mean $\mathrm{ADH}$ was 6.27 $\pm 1.47 \mathrm{~mm}$ before the surgery and improved to $10.63 \pm 1.32$ $\mathrm{mm}$ after the surgery (p-value $<0.05$ ). Some degree of subsidence occurred at the last follow-up and final $\mathrm{ADH}$ was 8.32 $\pm 1.08 \mathrm{~mm}$ (p-value $<0.05$ ). In same way, IH improved from $36.7 \pm 3.35 \mathrm{~mm}$ to $41.2 \pm 4.23 \mathrm{~mm}$ (p-value $<0.05$ ) and slightly decreased to $38.7 \pm 3.75 \mathrm{~mm}$ at the last exam (p-value < 0.05 ); however, we still achieved an increase of $\mathrm{IH}$. The mean preoperative SIA was $-3.35 \pm 3.44^{\circ}$ and postoperative SIA was $-6.85 \pm 3.01^{\circ}$ (p-value $<0.05$ ). At the final exam, SIA was -3.21 $\pm 3.61^{\circ}$, not statistically different between postoperative SIA and final exam SIA ( $p$-value $=0.813$ ).

\section{Complications}

We had no complications concerned with the surgery itself except one case of osteomyelitis. During the follow-up period, there was no cage related complication or soft tissue injury. The superficial osteomyelitis of iliac bone donor site developed in 1 patient and a culture study of the infection site confirmed Methicillin resistant staphylococcus aureus (MRSA)
Table. 3. Mean values of radiological parameters

\begin{tabular}{|c|c|c|c|c|}
\hline Parameters & Preoperative & Postoperative & $\begin{array}{l}\text { Last f/u } \\
\text { period }\end{array}$ & $p$ (ttest) \\
\hline $\mathrm{ADH}(\mathrm{mm})$ & $6.27 \pm 1.47$ & & $8.32 \pm 1.08$ & $\begin{array}{l}<0.05^{*} \\
<0.05^{\S}\end{array}$ \\
\hline $\mathrm{H}(\mathrm{mm})$ & $36.7 \pm 3.35$ & $41.2 \pm 4.23$ & $38.7 \pm 3.75$ & $\begin{array}{l}<0.05^{*} \\
<0.05^{\S}\end{array}$ \\
\hline $\operatorname{SIA}\left({ }^{\circ}\right)$ & $-3.35 \pm 3.44$ & $-6.85 \pm 3.01$ & $-3.21 \pm 3.61$ & $\begin{array}{l}<0.05^{*} \\
0.813^{\S}\end{array}$ \\
\hline
\end{tabular}

Values are means \pm SD.

${ }^{*}$ Comparison of preoperative and postoperative mean values.

${ }^{\S}$ Comparison of preoperative and last followup mean values.

infection. We performed local debridement and irrigation and treated with vancomycin intravenous treatment for 10 days. Infection was controlled and no problem occurred.

\section{DISCUSSION}

ACDF has been performed for treatment of cervical degenerative disease and applied to infectious disease, cervical trau$\mathrm{ma}$ and tumorous condition ${ }^{10}$. Clinically, ACDF with cage system began to be used regularly after clinical success of prospective research year $2000^{13}$. Single level ACDF with autograft shows over $95 \%$ of fusion rate and approximately $80 \%$ of neurologic improvement ${ }^{15,24,25)}$. Some reports postulated there was no need for fusion after cervical discectomy and fusion should be considered only when instability occurs ${ }^{32}$. The authors believe that discectomy alone aggravates instability and certain mechanical substitution is needed. The loss of disc height and increased motion affects pathophysiologic spondylosis. The limitation of a cage-alone procedure is weak initial me- 
chanical stability and subsidence to endplate. A cervical anterior plate and screw system provides reduction of kyphotic angulation, prevention of implant migration, and increases fusion rate and durable fixation. There may be, however, dysphasia due to plate and loosening, breakage of screw, plate migration and stress shield ${ }^{3,5,15)}$. Innovative development of surgical instrument have reduced complications of the anterior plate system. However, complications are still reported even though dynamic plate or self locking screw is suggested ${ }^{27}$.

The PEEK cages are biologically inactive which means they do not induce a corrosive reaction and provide high versatility and good mechanical properties while causing minimal artifacts on MRI and $\mathrm{CT}^{8,9)}$. Furthermore, excellent radiolucency gives information that surgeon can use to adjust the cage at an optimal location during operation, and bone fusion can be readily evaluated by plain $\mathrm{x}$-ray ${ }^{11,34)}$. Titanium spikes on upper and bottom can make easy to anchor the vertebral body and provide immediate fixation, therefore cage migration is prevented. The hollow inner space of cage provides an interface that promotes bone fusion ${ }^{23}$. Elastic modulus is defined as the capacity of returning to its initial shape when load is removed. The higher the elastic modulus the higher the forces needed to deform certain material. Lower elastic modulus shows a more natural characteristic with respect of bone material and lead to reduction of stress shield and increase bony fusion rate ${ }^{33)}$. Among several cervical implants, the elastic modulus of the PEEK approximates that of bony structure ${ }^{18)}$. High elastic mismatch between cage and bone can affect bone growth, promoting cortical thinning and subsidence in the case of metallic cages ${ }^{18,34}$. Generally, it is acceptable that bone fusion is achieved around 3 to 6 months after the surgery when using the PEEK cage. Cho et al. reported 100\% of bone fusion in forty cases was achieved by using PEEK cage comparing 93.1\% of bone fusion when using iliac tricortical bonegraft". In this study, we achieved $100 \%$ of fusion rate. Only cancellous bone from the iliac crest might be great role of increase fusion rate and small size of patient group might be another cause. The frequency of harvest autograft has decreased gradually, because of the relatively high rate of complications ${ }^{18)}$. Complications of tricortical iliac bone graft are various such as displacement bone graft, pseudoarthrosis, hematoma, pain, nerve injury and infection of donor site ${ }^{20)}$. The incidence of related complications has been reported to be as high as $20 \%$ to $50 \% \%^{1,28)}$. Moreover, the low stabilization support of iliac crest grafts requires instrumentation with anterior plate ${ }^{34)}$. To reduce complications related with donor site, many types of material have been studied to substitute autologous bone, but none of these have showed advantage over autologous bone ${ }^{6,16}$. Many complications related with iliac bone graft have been reduced with the use of cage system ${ }^{23}$. In our patient group, the wound incision on the donor site was performed minimally and harvested only small amount of cancellous bone to minimize related complications.

The question of the best implant for ACDF is still controversial. Numerous materials have been tried to substitute for autologous bone graft to reduce donor site related complications. The ultimate material could provide immediate structural support and osteogenic intergration ${ }^{233}$.

Since introduction of the cervical cage, numerous types of cage have been designed; however subsidence of cage was reported frequently. Ha et al. studied subsidence in standalone Solis ${ }^{\circledR}$ cage and found $8.1 \%$ of cages had subsidence greater than $3 \mathrm{~mm}^{12}$. We observed several cases where subsidence occurred, but it did not affect prognosis. Matge et al. noted that a decrease of disc height after operation did not affect clinical outcome ${ }^{20}$. Lee et al. found that subsidence occurred on radiologic evaluation at last follow-up when they used $\mathrm{DMB}$ rather than autologous bone graft ${ }^{23)}$. However, our data shows that at 36 months follow-up IH is still maintained compared to preoperative $\mathrm{IH}$ which implies autologous bone graft helps earlier bone fusion than DBM.

Cervical interbody fusion causes acceleration of degeneration at adjacent levels by increased stress ${ }^{2,721)}$. Symptomatic adjacent segment problems occur at rate of $2.9 \%$ per year during ten years after ACDF with autologous bone graft, the risk was lower in multilevel ACDF than in single level, and the fusion rate declines as the number of involved levels increase $^{11,14)}$. In our study, we could not find degeneration of adjacent levels, but we concluded that this is due to small size of patient group.

In current study, the complications of ACDF with the PEEK cage did not include breaking, pseudoarthrosis, kyphotic angulation, protrusion of cage itself, and severe subsidence. However, one patient suffered from infection of donor site. Local heating and pus discharge occurred at right iliac crest where cancellous bone was harvested and culture study performed. Methicillin-resistant staphylococcus aureus (MRSA) was detected and vancomycin was prescribed for a week.

To establish a role of the PEEK cage in ACDF, we need prospective larger series and longer follow up studies. The authors searched many articles to find a long term follow-up study for clinical outcome after ACDF with PEEK cage longer than 36 months but we believe that this study is the first report for long term follow-up.

\section{CONCLUSION}

ACDF with the Solis cage provides favorable clinical outcomes and radiologic fusion rates comparing with other classi- 
cal or alternative cervical fusion methods. It does not cause plate relating complication and radiologic opacity of cage spike enable to locate a cage at optimal location by using fluoroscope. There have been several reports that describe the efficacy of ACDF with PEEK cage for short term follow-up, but long term (more than 24 months) follow-up studies are rare. We present here a long term follow-up study for ACDF with PEEK cage and its clinical efficacy is favorable.

\section{REFERENCES}

1. Arrington ED, Smith WJ, Chambers HG, Bucknell AL, Davino NA: Complications of iliac crest bone graft harvesting. Clin Orthop Relat Res: 300-309, 1996

2. Baba H, Furusawa N, Imura S, Kawahara N, Tsuchiya H, Tomita $\mathrm{K}$ : Late radiographic findings after anterior cervical fusion for spondylotic myeloradiculopathy. Spine (Phila Pa 1976) 18:21672173, 1993

3. Bohler J, Gaudernak T: Anterior plate stabilization for fracture-dislocations of the lower cervical spine. J Trauma 20:203205, 1980.

4. Brantigan JW, Steffee AD, Geiger JM: A carbon fiber implant to aid interbody lumbar fusion. Mechanical testing. Spine (Phila Pa 1976) 16:S277-282, 1991

5. Brown JA, Havel P, Ebraheim N, Greenblatt SH, Jackson WT: Cervical stabilization by plate and bone fusion. Spine (Phila Pa 1976) 13:236-240, 1988

6. Chau AM, Mobbs RJ: Bone graft substitutes in anterior cervical discectomy and fusion. Eur Spine J 18:449-464, 2009

7. Cherubino P, Benazzo F, Borromeo U, Perle S: Degenerative arthritis of the adjacent spinal joints following anterior cervical spinal fusion: clinicoradiologic and statistical correlations. Ital J Orthop Traumatol 16:533-543, 1990

8. Cho DY, Lee WY, Sheu PC: Treatment of multilevel cervical fusion with cages. Surg Neurol 62:378-385, discussion 385-376, 2004

9. Cho DY, Liau WR, Lee WY, Liu JT, Chiu CL, Sheu PC: Preliminary experience using a polyetheretherketone (PEEK) cage in the treatment of cervical disc disease. Neurosurgery 51:13431349; discussion 1349-1350, 2002

10. Connolly ES, Seymour RJ, Adams JE: Clinical evaluation of anterior cervical fusion for degenerative cervical disc disease. J Neurosurg 23:431-437, 1965

11. Demircan MN, Kutlay AM, Colak A, Kaya S, Tekin T, Kibici K, et al: Multilevel cervical fusion without plates, screws or autogenous iliac crest bone graft. J Clin Neurosci 14:723-728, 2007

12. Ha SK, Park JY, Kim SH, Lim DJ, Kim SD, Lee SK: Radiologic Assessment of Subsidence in Stand-Alone Cervical Polyetheretherketone (PEEK) Cage. J Korean Neurosurg Soc 44:370-374, 2008

13. Hacker RJ, Cauthen JC, Gilbert TJ, Griffith SL: A prospective randomized multicenter clinical evaluation of an anterior cervical fusion cage. Spine (Phila Pa 1976) 25:2646-2654; discussion 2655, 2000

14. Hilibrand AS, Carlson GD, Palumbo MA, Jones PK, Bohlman
$\mathrm{HH}$ : Radiculopathy and myelopathy at segments adjacent to the site of a previous anterior cervical arthrodesis. J Bone Joint Surg Am 81:519-528, 1999

15. Kaiser MG, Haid RW, Jr., Subach BR, Barnes B, Rodts GE, Jr.: Anterior cervical plating enhances arthrodesis after discectomy and fusion with cortical allograft. Neurosurgery 50: 229236; discussion 236-228, 2002

16. Kim SY PK, Jung SS, Chung SY, Kim SM, Park MS, Kim HK: An Early Comparative Analysis of the Use of Autograft Versus Allograft in Anterior Cervical Discectomy and Fusion. Korean J Spine 9:142-146, 2012

17. Madawi AA, Powell M, Crockard HA: Biocompatible osteoconductive polymer versus iliac graft. A prospective comparative study for the evaluation of fusion pattern after anterior cervical discectomy. Spine (Phila Pa 1976) 21:2123-2129; discussion 2129-2130, 1996

18. Mastronardi L, Ducati A, Ferrante L: Anterior cervical fusion with polyetheretherketone (PEEK) cages in the treatment of degenerative disc disease. Preliminary observations in 36 consecutive cases with a minimum 12-month follow-up. Acta Neurochir (Wien) 148:307-312; discussion 312, 2006

19. Matge G: Anterior interbody fusion with the BAK-cage in cervical spondylosis. Acta Neurochir (Wien) 140:1-8, 1998

20. Matge G, Leclercq TA: Rationale for interbody fusion with threaded titanium cages at cervical and lumbar levels. Results on 357 cases. Acta Neurochir (Wien) 142:425-433; discussion 434, 2000

21. Matsunaga S, Kabayama S, Yamamoto T, Yone K, Sakou T, Nakanishi K: Strain on intervertebral discs after anterior cervical decompression and fusion. Spine (Phila Pa 1976) 24:670675, 1999

22. McAfee PC, Bohlman HH: One-stage anterior cervical decompression and posterior stabilization with circumferential arthrodesis. A study of twenty-four patients who had a traumatic or a neoplastic lesion. J Bone Joint Surg Am 71:78-88, 1989

23. Park HW, Lee JK, Moon SJ, Seo SK, Lee JH, Kim SH: The efficacy of the synthetic interbody cage and Grafton for anterior cervical fusion. Spine (Phila Pa 1976) 34:E591-595, 2009

24. Sampath P, Bendebba M, Davis JD, Ducker T: Outcome in patients with cervical radiculopathy. Prospective, multicenter study with independent clinical review. Spine (Phila Pa 1976) 24:591597, 1999

25. Sampath P, Bendebba M, Davis JD, Ducker TB: Outcome of patients treated for cervical myelopathy. A prospective, multicenter study with independent clinical review. Spine (Phila Pa 1976) 25:670-676, 2000

26. Shad A, Leach JC, Teddy PJ, Cadoux-Hudson TA: Use of the Solis cage and local autologous bone graft for anterior cervical discectomy and fusion: early technical experience. J Neurosurg Spine 2:116-122, 2005

27. Shapiro S: Banked fibula and the locking anterior cervical plate in anterior cervical fusions following cervical discectomy. J Neurosurg 84:161-165, 1996

28. Silber JS, Anderson DG, Daffner SD, Brislin BT, Leland JM, Hilibrand AS, et al: Donor site morbidity after anterior iliac crest bone harvest for single-level anterior cervical discectomy and fusion. Spine (Phila Pa 1976) 28:134-139, 2003

29. Sonntag VK, Klara P: Controversy in spine care. Is fusion neces- 
sary after anterior cervical discectomy? Spine (Phila Pa 1976) 21:1111-1113, 1996

30. Stauffer ES, Kelly EG: Fracture-dislocations of the cervical spine. Instability and recurrent deformity following treatment by anterior interbody fusion. J Bone Joint Surg Am 59:45-48, 1977

31. Suh PB, Kostuik JP, Esses SI: Anterior cervical plate fixation with the titanium hollow screw plate system. A preliminary report. Spine (Phila Pa 1976) 15:1079-1081, 1990

32. Thorell W, Cooper J, Hellbusch L, Leibrock L: The long-term clinical outcome of patients undergoing anterior cervical dis- cectomy with and without intervertebral bone graft placement. Neurosurgery 43:268-273; discussion 273-264, 1998

33. Wenz LM, Merritt K, Brown SA, Moet A, Steffee AD: In vitro biocompatibility of polyetheretherketone and polysulfone composites. J Biomed Mater Res 24:207-215, 1990

34. Zhou J, Xia Q, Dong J, Li X, Zhou X, Fang T, et al: Comparison of stand-alone polyetheretherketone cages and iliac crest autografts for the treatment of cervical degenerative disc diseases. Acta Neurochir (Wien) 153:115-122, 2010 